\title{
NOTES
}

\section{Living Polymerization of [o-(Trimethylsilyl)phenyl]acetylene by Molybdenum-Based Three-Component Catalysts}

\author{
Toshio Masuda,* Jun'Ichi Fujimori, Mohamad Zaki Ab. Rahman, \\ and Toshinobu Higashimura* \\ Department of Polymer Chemistry, Kyoto University, Kyoto 606-01, Japan
}

(Received November 9, 1992)

\begin{abstract}
KEY WORDS [o-(Trimethylsilyl)phenyl]acetylene / Substituted Acetylene / Metathesis Polymerization / Transition-Metal Catalyst / Living Polymerization / Silicon-Containing Polymer /
\end{abstract}

Living polymerization induced by transition-metal catalysts has recently made great progress. For instance, Grubbs ${ }^{1}$ and Schrock ${ }^{2}$ have developed many living systems in ringopening metathesis polymerization (ROMP) of cycloolefins by using well-defined metalcarbene initiators. The authors have found that molybdenum-based three-component catalysts, i.e., $\mathrm{MoOCl}_{4}-$ (or $\left.\mathrm{MoCl}_{5}\right)-n-\mathrm{Bu}_{4} \mathrm{Sn}-$ EtOH effect living polymerization of substituted acetylenes such as 1-chloro-1-octyne ${ }^{3,4}$ and $\left[o\right.$-(trifluoromethyl)phenyl] acetylene. ${ }^{5}$

Silicon-containing polyacetylenes are characterized by unique properties like high gas permeability. ${ }^{6}$ Examples of such polymers with high molecular weight include poly[1-(trimethylsilyl)-1-propyne] and poly[[o-(trimethylsilyl)phenyl]acetylene] [poly $\left.\left(o-\mathrm{Me}_{3} \mathrm{SiPA}\right)\right]$. The former polymer is obtained with $\mathrm{Nb}$ and Ta catalysts, while the latter with Mo and W catalysts. $^{7}$ Thus it is interesting to examine whether [o-(trimetylsilyl)phenyl] acetylene (o$\mathrm{Me}_{3} \mathrm{SiPA}$ ) will afford a living polymer or not by use of the Mo-based three-component catalysts.

In the present note, we report on the living polymerization of $o-\mathrm{Me}_{3} \mathrm{SiPA}$ effected by $\mathrm{MoCl}_{5^{-}}$and $\mathrm{MoOCl}_{4}$-based catalysts and the effects of polymerization conditions on the molecular weight distribution (MWD) of polymers. The living nature of the polymerization by $\mathrm{MoCl}_{5}-\left(\right.$ or $\left.\mathrm{MoOCl}_{4}\right)-n-\mathrm{Bu}_{4} \mathrm{Sn}-\mathrm{EtOH}$ catalysts has been proved by both small polydispersity ratios close to unity and increases of polymer molecular weight proportional to monomer consumption.

\section{EXPERIMENTAL}

The synthesis of $o-\mathrm{Me}_{3} \mathrm{SiPA}$ followed the same method as described previously. ${ }^{8}$ The monomer was distilled twice at reduced pressure from calcium hydride before use: bp $85^{\circ} \mathrm{C} / 10 \mathrm{mmHg}$, purity $>99 \%$ (by gas chromatography (GC)). Transition metal chlorides (Strem Chemicals; purity $>99 \%$ ) and organometallic cocatalysts were commercially obtained, and used without further purification with care being taken not to be decomposed by moisture and/or air. Oxygen-containing compounds such as ethanol $(\mathrm{EtOH})$ were distilled before use. Toluene as polymerization solvent was purified by a standard method.

All the procedures for polymerization were

* To whom correspondence should be addressed. 
carried out under dry nitrogen with use of pre-baked flasks equipped with a three-way stopcock. The catalyst solution was prepared by dissolving $\mathrm{MoCl}_{5}$ (or $\mathrm{MoOCl}_{4}$ ) and $n$ $\mathrm{Bu}_{4} \mathrm{Sn}$ in toluene, aging at $30^{\circ} \mathrm{C}$ for $15 \mathrm{~min}$, then adding $\mathrm{EtOH}$, and finally aging at $30^{\circ} \mathrm{C}$ for an additional $15 \mathrm{~min}$. Detailed polymerization procedures were described before. ${ }^{5}$ Monomer conversions were determined by measuring the initial and final monomer concentrations by GC (silicone DC $3 \mathrm{~m}$, $170^{\circ} \mathrm{C}$ ).

The MWD curves of polymers were observed by gel permeation chromatography (GPC) using a Jasco Trirotar liquid chromatograph (Shodex A803, A804, and A805 polystyrene gel columns, eluent $\mathrm{CHCl}_{3}$ ), and the number-and weight-average molecular weights ( $\bar{M}_{n}$ and $\bar{M}_{w}$, respectively) of polymers were calculated on the basis of a polystyrene calibration.

\section{RESULTS AND DISCUSSION}

\section{Polymerization by $\mathrm{MoCl}_{5}$-Based Catalysts}

Polymerization of $o-\mathrm{Me}_{3} \mathrm{SiPA}$ by $\mathrm{MoCl}_{5}$ based catalysts was studied using three kinds of catalysts, i.e., $\mathrm{MoCl}_{5}$ alone, $\mathrm{MoCl}_{5}-n$ $\mathrm{Bu}_{4} \mathrm{Sn}(1: 1)$ and $\mathrm{MoCl}_{5}-n-\mathrm{Bu}_{4} \mathrm{Sn}-\mathrm{EtOH}(1$ : $1: 0.5)$. The polymerizations were carried out in toluene at $30^{\circ} \mathrm{C}$ for $1 \mathrm{~h}$, and $100 \%$ monomer conversions were observed irrespective of the number of catalyst components. As seen in Figure 1, three-component catalyst, $\mathrm{MoCl}_{5}-n-\mathrm{Bu}_{4} \mathrm{Sn}-\mathrm{EtOH}$ produced a polymer whose polydispersity ratio is smaller than 1.1, whereas the MWDs with the two other catalyst systems, were rather broad $\left(\bar{M}_{w} / \bar{M}_{n}>\right.$ 1.3). Smaller amounts of polymer having higher molecular weight were formed in the polymerizations using $\mathrm{MoCl}_{5}$ and $\mathrm{MoCl}_{5}-n$ $\mathrm{Bu}_{4} \mathrm{Sn}$, but no such fraction formed with $\mathrm{MoCl}_{5}-n-\mathrm{Bu}_{4} \mathrm{Sn}-\mathrm{EtOH}$. Thus, the $\mathrm{MoCl}_{5}-n$ $\mathrm{Bu}_{4} \mathrm{Sn}-\mathrm{EtOH}$ catalyst proved to yield poly $(o-$ $\mathrm{Me}_{3} \mathrm{SiPA}$ ) with narrow MWDs. Hence, a detailed study was carried out as shown below

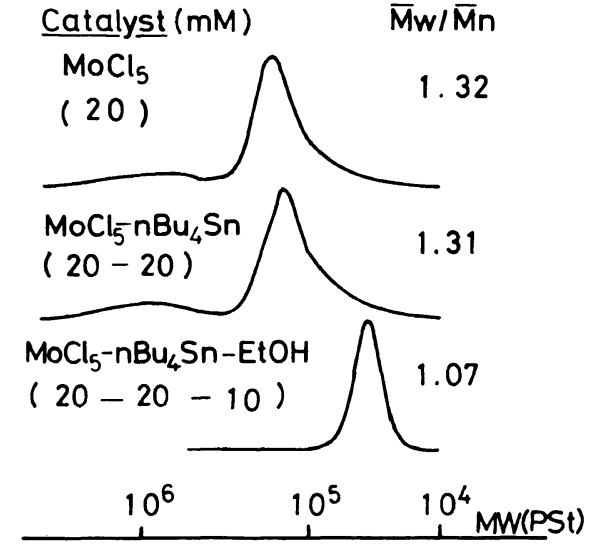

Figure 1. MWD curves of poly $\left(o-\mathrm{Me}_{3} \mathrm{SiPA}\right) \mathrm{s}$ obtained with $\mathrm{MoCl}_{5}$-based catalysts (polymerized in toluene at $30^{\circ} \mathrm{C}$ for $1 \mathrm{~h} ;[\mathrm{M}]_{0}=0.50 \mathrm{M}$; the conversions $100 \%$ ).

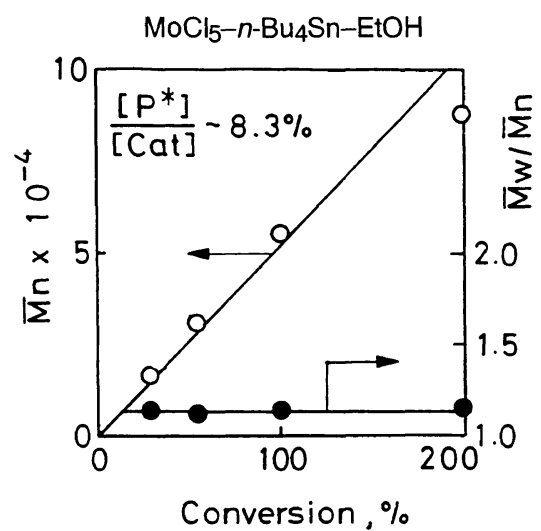

Figure 2. $\bar{M}_{n}$ and $\bar{M}_{w} / \bar{M}_{n}$ of poly $\left(o-\mathrm{Me}_{3} \mathrm{SiPA}\right)$ as a function of monomer conversion in the "monomer addition experiment" with use of $\mathrm{MoCl}_{5}-n-\mathrm{Bu}_{4} \mathrm{Sn}-\mathrm{EtOH}$ $(1: 1: 0.5)$ (polymerized in toluene at $30^{\circ} \mathrm{C}$ for $1 \mathrm{~h}$; $\left.[\mathrm{M}]_{\mathrm{o}}=[\mathrm{M}]_{\text {added }}=0.50 \mathrm{M} ;\left[\mathrm{MoCl}_{5}\right]=20 \mathrm{mM}\right)$.

by using this three-component catalyst.

Living nature of the polymerization was examined by so called "monomer addition experiment" (Figure 2). The $\bar{M}_{n}$ of polymer increases in proportion to conversion and also in the second stage where additional monomer is supplied to a polymerization system after all the monomer has been consumed. Since the polydispersity ratio of polymer remained small, this polymerization is concluded to be living. 
Table I. Effect of Cocatalysts on the Polymerization of $o-\mathrm{Me}_{3} \mathrm{SiPA}$ by $\mathrm{MoCl}_{5}$-cocatalyst-EtOH $(1: 1: 0.5)^{\mathrm{a}}$

\begin{tabular}{|c|c|c|c|c|c|c|}
\hline \multirow{2}{*}{ Cocatalyst } & \multirow{2}{*}{$\frac{\text { Time }}{\min }$} & \multirow{2}{*}{$\begin{array}{c}\text { Conversion } \\
\%\end{array}$} & \multicolumn{4}{|c|}{ Polymer ${ }^{b}$} \\
\hline & & & Yield $/ \%$ & $\bar{M}_{n}$ & $\bar{M}_{w} / \bar{M}_{n}$ & {$\left[\mathrm{P}^{*}\right] /[\mathrm{Mo}]$} \\
\hline$n-\mathrm{Bu}_{4} \mathrm{Sn}$ & 60 & 100 & 88 & 43,000 & 1.07 & 0.010 \\
\hline $\mathrm{Me}_{4} \mathrm{Sn}$ & 60 & 100 & 96 & 64,000 & 1.11 & 0.068 \\
\hline $\mathrm{Ph}_{4} \mathrm{Sn}$ & 180 & 54 & 47 & 86,000 & 1.47 & 0.051 \\
\hline $\mathrm{Et}_{3} \mathrm{SiH}$ & 60 & 81 & 67 & 79,000 & 1.21 & 0.055 \\
\hline
\end{tabular}

a Polymerized in toluene at $30^{\circ} \mathrm{C}:[\mathrm{M}]_{0}=0.50 \mathrm{M} ;\left[\mathrm{MoCl}_{5}\right]=20 \mathrm{mM}$.

b $\mathrm{MeOH}$-insoluble part.

Table II. Effect of Oxygen-Containing Compounds (O-compd) on the Polymerization of $o-\mathrm{Me}_{3} \mathrm{SiPA}$ by $\mathrm{MoCl}_{5}-n-\mathrm{Bu}_{4} \mathrm{Sn}-\mathrm{O}$-compd $(1: 1: 0.5)^{\mathrm{a}}$

\begin{tabular}{|c|c|c|c|c|c|c|}
\hline \multirow{2}{*}{ O-compd } & \multirow{2}{*}{$\frac{\text { Time }}{\min }$} & \multirow{2}{*}{$\begin{array}{c}\text { Conversion } \\
\%\end{array}$} & \multicolumn{4}{|c|}{ Polymer } \\
\hline & & & Yield $/ \%$ & $\bar{M}_{n}$ & $\bar{M}_{w} / \bar{M}_{n}$ & {$\left[\mathrm{P}^{*}\right] /[\mathrm{Mo}]$} \\
\hline None & 60 & 100 & 95 & 99,000 & 1.31 & 0.048 \\
\hline $\mathrm{EtOH}$ & 60 & 100 & 88 & 43,000 & 1.07 & 0.10 \\
\hline $\mathrm{CH}_{3} \mathrm{COOH}$ & 60 & 100 & 94 & 66,000 & 1.11 & 0.066 \\
\hline $\mathrm{CH}_{3} \mathrm{COO}-n-\mathrm{Bu}$ & 60 & 100 & 95 & 73,000 & 1.14 & 0.060 \\
\hline Acetone & 60 & 100 & 95 & 69,000 & 1.24 & 0.063 \\
\hline $\mathrm{H}_{2} \mathrm{O}$ & 120 & 98 & 95 & 97,000 & 1.12 & 0.045 \\
\hline
\end{tabular}

a Polymerized in toluene at $30^{\circ} \mathrm{C}:[\mathrm{M}]_{\mathrm{o}}=0.50 \mathrm{M} ;\left[\mathrm{MoCl}_{5}\right]=20 \mathrm{mM}$.

Table I shows the effect of some organometallic cocatalysts on the polymerization of $o-\mathrm{Me}_{3} \mathrm{SiPA}$ by $\mathrm{MoCl}_{5}$-cocatalyst-EtOH $(1: 1: 0.5)$. The MWDs of the polymers were quite narrow with use of $n-\mathrm{Bu}_{4} \mathrm{Sn}$ and $\mathrm{Me}_{4} \mathrm{Sn}$ as cocatalysts. In contrast, $\mathrm{Ph}_{4} \mathrm{Sn}$, and $\mathrm{Et}_{3} \mathrm{SiH}$ as cocatalysts gave polymers with rather broad MWDs $\left(\bar{M}_{w} / \bar{M}_{n} c a\right.$. $\left.1.2-1.5\right)$. Further, the latter two cocatalysts depressed the monomer conversion. These clearly show that the activity of the $\mathrm{MoCl}_{5}$-cocatalyst-EtOH system strongly depends on the nature of cocatalyst. At present it is virtually accepted that the propagating species of the polymerization are metal carbenes. Hence one can assume from the propagating end-to-catalyst ratios $\left(\left[\mathrm{P}^{*}\right] /[\mathrm{Mo}]\right)$ in Table I that $n-\mathrm{Bu}_{4} \mathrm{Sn}$ as cocatalyst provides the most stable metal carbene.

Table II details the results of the effect of oxygen-containing compounds on the polymerization of $o-\mathrm{Me}_{3} \mathrm{SiPA}$. Oxygen-containing compounds other than acetone as third components of catalyst gave fairly small values of $\bar{M}_{w} / \bar{M}_{n}(\sim 1.1)$. This finding means that the oxygen-containing compounds are useful for the formation of stable metal carbenes. It is worth noting that acetic acid, $n$-butyl acetate and $\mathrm{H}_{2} \mathrm{O}$ show similar effectiveness to one another on the basis of their $\bar{M}_{w} / M_{n}$ ratios $(\sim 1.1)$. This suggests that the presence of a labile proton in the oxygen-containing compound is not necessarily required for living polymerization of $o-\mathrm{Me}_{3} \mathrm{SiPA}$.

\section{Polymerization by $\mathrm{MoOCl}_{4}$-Based Catalysts}

Previous studies have shown that the effects of $\mathrm{MoOCl}_{4}$-based catalysts on the polymerization of substituted acetylenes resemble those with the $\mathrm{MoCl}_{5}$-based counterpart. ${ }^{3,5}$ How- 


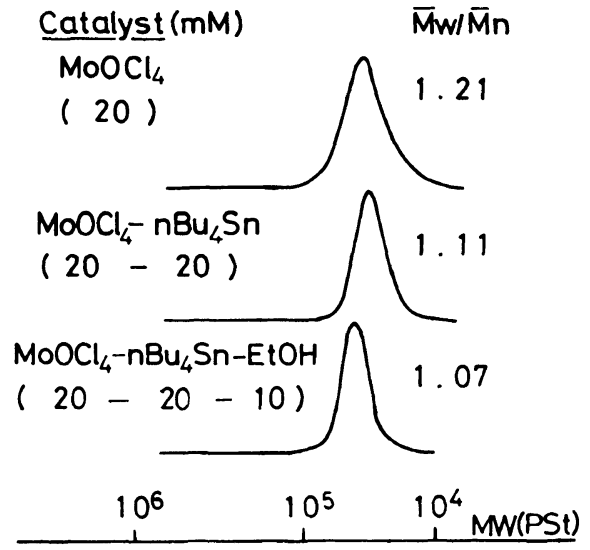

Figure 3. MWD curves of poly $\left(o-\mathrm{Me}_{3} \mathrm{SiPA}\right)$ s obtained with $\mathrm{MoOCl}_{4}$-based catalysts (polymerized in toluene at $30^{\circ} \mathrm{C}$ for $1 \mathrm{~h} ;[\mathrm{M}]_{\mathrm{o}}=0.50 \mathrm{M}$; the conversions $100 \%$ ).

ever, better results with respect to living polymerization have been obtained with $\mathrm{MoOCl}_{4}$ than with $\mathrm{MoCl}_{5}$. It has also been found through molecular orbital calculations that the presence of metal-oxygen bond provides higher stabilities of metal carbene and metallacyclobutane and effects the metathesis reaction more smoothly. ${ }^{9}$ Thus the following studies were carried out to further examine the above phenomena in the polymerization of $o-\mathrm{Me}_{3} \mathrm{SiPA}$ using $\mathrm{MoOCl}_{4}$-based catalysts. For the sake of comparison, the polymerization reactions were carried out under the same conditions as for $\mathrm{MoCl}_{5}$-based catalysts.

As seen in Figure 3 , the $\bar{M}_{w} / \bar{M}_{n}$ of polymer was below 1.10 with the $\mathrm{MoOCl}_{4}-n-\mathrm{Bu}_{4} \mathrm{Sn}$ EtOH catalyst, but the ratios with $\mathrm{MoOCl}_{4}-$ $n-\mathrm{Bu}_{4} \mathrm{Sn}$ and $\mathrm{MoOCl}_{4}$ alone as catalysts were larger, i.e., 1.11 and 1.21, respectively. Formation of a higher molecular weight fraction was not observed in these polymerizations using $\mathrm{MoOCl}_{4}$-based catalysts.

Livingness of the propagating species in the polymerization by $\mathrm{MoOCl}_{4}-n-\mathrm{Bu}_{4} \mathrm{Sn}-\mathrm{EtOH}$ was confirmed by a narrow MWD and an increase of polymer molecular weight proportional to monomer consumption (Figure 4). When compared with the polymerization by $\mathrm{MoCl}_{5}-n-\mathrm{Bu}_{4} \mathrm{Sn}-\mathrm{EtOH}$ (see Figure 1), both

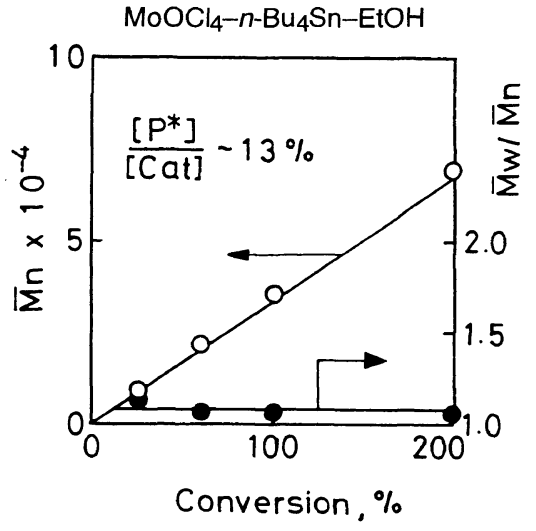

Figure 4. $\bar{M}_{n}$ and $\bar{M}_{w} / \bar{M}_{n}$ of poly $\left(o-\mathrm{Me}_{3} \mathrm{SiPA}\right)$ as a function of monomer conversion in the "monomer addition experiment" with use of $\mathrm{MoOCl}_{4}-n-\mathrm{Bu}_{4} \mathrm{Sn}-\mathrm{EtOH}$ $(1: 1: 0.5)$ (polymerized in toluene at $30^{\circ} \mathrm{C}$ for $1 \mathrm{~h}$; $\left.[\mathrm{M}]_{\mathrm{o}}=[\mathrm{M}]_{\text {added }}=0.50 \mathrm{M} ;\left[\mathrm{MoOCl}_{4}\right]=20 \mathrm{mM}\right)$.

give the same polydispersity ratio of 1.07 . However, more perfect living polymerization can be achieved by using $\mathrm{MoOCl}_{4}-n-\mathrm{Bu}_{4} \mathrm{Sn}-$ $\mathrm{EtOH}$ than $\mathrm{MoCl}_{5}-n-\mathrm{Bu}_{4} \mathrm{Sn}-\mathrm{EtOH}$ from the viewpoint of the ratio of the propagating species to the Mo catalyst $\left(\left[\mathrm{P}^{*}\right] /[\mathrm{Mo}]\right)$, i.e., initiator efficiency. That is, the $\left[\mathrm{P}^{*}\right] /[\mathrm{Mo}]$ ratio was 0.13 for $\mathrm{MoOCl}_{4}-n-\mathrm{Bu}_{4} \mathrm{Sn}-\mathrm{EtOH}$, which is larger than 0.08 for $\mathrm{MoCl}_{5}-n-\mathrm{Bu}_{4} \mathrm{Sn}-$ EtOH (see Figures 2 and 3).

\section{CONCLUSIONS}

The $\mathrm{MoCl}_{5}$-(or $\mathrm{MoOCl}_{4}$ )- $n$ - $\mathrm{Bu}_{4} \mathrm{Sn}-\mathrm{EtOH}$ catalyst systems effected living polymerization of $o-\mathrm{Me}_{3} \mathrm{SiPA}$ to give polymers with narrow MWDs $\left(\bar{M}_{w} / \bar{M}_{n}<1.1\right)$. In these polymerizations, the $\bar{M}_{n}$ of polymer increased in direct proportion to monomer conversion and even after additional monomer was supplied to a completely polymerized system. As living polymerization catalyst, $\mathrm{MoOCl}_{4}-n-\mathrm{Bu}_{4} \mathrm{Sn}-$ EtOH surpassed $\mathrm{MoCl}_{5}-n-\mathrm{Bu}_{4} \mathrm{Sn}-\mathrm{EtOH}$ on the basis of their initiator efficiencies $\left(\left[\mathrm{P}^{*}\right] /\right.$ $[\mathrm{Mo}]=0.13$ vs. 0.08$)$.

Acknowledgment. This research was partly supported by a Grant-in-Aid for Scientific 
Research on Priority Areas "New Functionality Materials" from the Ministry of Education, Science, and Culture of Japan.

\section{REFERENCES}

1. For a review, see: B. M. Novak, W. Risse, and R. H. Grubbs, Adv. Polym. Sci., 102, 47 (1992).

2. For a review, see: R. R. Schrock, Acc. Chem. Res., 23, 158 (1990).

3. T. Masuda, T. Yoshimura, and T. Higashimura, Macromolecules, 22, 3804 (1989).

4. T. Yoshimura, T. Masuda, and T. Higashimura,
Macromolecules, 21, 1899 (1988).

5. T. Masuda, K. Mishima, J. Fujimori, M. Nishida, H. Muramatsu, and T. Higashimura, Macromolecules, 25, 1401 (1992).

6. T. Masuda and T. Higashimura, "Silicon-Based Polymer Science, (Adv. Chem. Ser. No. 224),” J. M. Zeigler, F. W. G. Fearon, Ed., American Chemical Society, 1990, Chapter 35.

7. T. Masuda, T. Hamano, K. Tsuchihara, and T. Higashimura, Macromolecules, 23, 1374 (1990).

8. L. Brandsma, "Preparative Acetylenic Chemistry," 2nd ed, Elsevier, Amsterdam, 1988, p 124.

9. A. K. Rappe and W. A. Goddard, J. Am. Chem. Soc., 104, 448 (1982). 